\title{
HUBUNGAN KEPATUHAN ANTENATAL CARE (ANC) DENGAN KECEMASAN IBUHAMIL TRIMESTER III DALAM MENGHADAPI PERSALINAN DI DESA SUMBERMULYO,JOGOROTO KABUPATEN JOMBANG
}

\author{
Correlation Between Antenatal Care (ANC) Adherence With $3^{\text {rd }}$ Trimester Pregnant \\ Women Anxiety Facing Labor In Sumbermulyo Village \\ Jogoroto, Jombang District
}

\author{
Yanti M. Missa, Ahmad Nur Khori, Shanti Rosmaharani* \\ Stikes Pemkab Jombang \\ *shanti.rosmaharani@gmail.com
}

\begin{abstract}
ABSTRAK
Angka kecemasan pada ibu hamil trimester III menunjukkan cukup tinggi itu disebabkan karena ibu hamil kurang patuh dalam melakukan pemeriksaan kehamilan. Dampak dari ibu hamil yang tidak mengikuti ANC adalah ibu hamil kurang mendapatkan informasi tentang persiapan persalinan sehingga pada saat akan menghadapi persalinan kecemasannya meningkat. Penelitian ini bertujuan menganalisis hubungan kepatuhan antenatale care (ANC) dengan kecemasanibu hamil trimester III dalam menghadapi persalinan di Bidan Praktek Mandiri (BPM) Yuni Widaryanti Desa Sumber Mulyo Kecamatan Jogoroto Kabupaten Jombang.

Desain penelitian yang digunakan adalah cross sectional. Populasipenelitianiniadalahibu hamil primigravida trimester III Bulan Mei - Juni di Wilayah Kerja BPM Yuni Widaryanti sebanyak 33 Orang. Teknik sampling menggunakan total sampling. Variable independen kepatuhan ANC, variable dependen kecemasan ibu hamil trimester III. Instrument untuk kepatuhan ANC menggunakan observasi sedangkan kecemasa $\mathrm{n}$ ibu hamil trimester III menggunakan kuesioner. Uji statistic yang dipakai Rank Spearman.

Analisa data rank spearman dengan nilai signifikan $\alpha=0,05$ diperoleh hasil perhitungan dengan nilai $\rho$ value 0,017, artinya adanya hubungan antara kepatuhan antenatal care (ANC) dengan kecemasan ibu hamil trimester III dalam menghadapi persalinan.

Berdasarkan hasil penelitian diharapkan ibu hamil lebih termotivasi dalam melakukan pemeriksaan kehamilan agar ibu dapat menjaga kondisi kesehatan serta mampu mengatasi kecemasan ibu pada saat menghadapi persalinan.
\end{abstract}

Kata kunci : Kepatuhan, ANC, Kecemasan

\section{ABSTRACT}

Elderly people are susceptible to illness ,one of them is stress, and the thing that can causes stress is Anxiety rate in pregnant woman of trimester III indicate high enough that caused by pregnant mother less dutiful in doing pregnancy examination. The impact of pregnant women who do not follow the ANC is that pregnant women have less informed about the preparation of labor so that they will face the increased anxiety. This study aims to analyze the correlation of antenatal care (ANC) compliance with anxiety of pregnant mother of third trimester to face laboring in self - employment midwife YuniWidaryanti in SumberMulyo Village JogorotoJombang.

The design of this study used cross sectional. The population of this study was pregnant primigravida woman in third trimester at May - June in Working Area of self - employment midwife Yuni Widaryanti as much as 33 0rang. The sampling technique used total sampling. The variable Independent was ANC compliance, the dependent variable was anxiety of third trimester pregnant woman. Instruments for ANC compliance used observation while the third trimester pregnant anxiety used questionnaire. Statistic test used Rank Spearman.

Spearman rank data analysis with significant value $\alpha=0,05$ got result of calculation with $\rho$ value 0,017 , it means that the existence of correlation between antenatal care (ANC) compliance with anxiety of third trimester pregnant woman in facing childbirth.

Based on the results of the study was expected that pregnant mothers were more motivated in doing the examination of pregnancy so that mothers could maintain health conditions and able to overcome maternal anxiety at the time of childbirth.

Keywords: Compliance, ANC, Anxiety 


\section{PENDAHULUAN}

Masalah yang sering ditemui banyak ibu hamil yang tidak teratur melakukan antenatale care (ANC) hal ini bertolak belakang dengan program pemerintah untuk mengurangi angka kesakitan pada ibu hamil dan bersalin tinggi, rendahnya cakupan Kunjungan pertama (K1) dan Kunjungan keempat (K4) menyebabkan angka kematian ibu dan bayi masih relatif tinggi (Januardi, 2014). Kecemasan menjelang persalinan umum dialami oleh ibu meskipun persalinan adalah suatu hal yang fisiologis, namun didalam menghadapi proses persalinan terjadi serangkaian perubahan fisik dan psikologis (Saifudin, 2014). Kecemasan pada saat persalinan hingga saat ini merupakan fenomena yang cukup banyak terjadi pada ibu hamil trimester III menjelang persalinan.

Menurut Bali Post tahun 2015 di Amerika Serikat, pada tahun 2014 jumlah persalinan normal sebanyak 12.045 orang dan persalinan Sectio Caesarea (SC) sebanyak 9.672 orang. Penelitian yang dilakukan oleh Barbara di Indonesia pada tahun 2014 hampir 66,2\% ibu cemas terhadap proses persalinan yang akan dihadapinya.Studi yang dilakukan Creasy (2013) di RS Cipto Mangunkusumo Jakarta dari 5429 ibu yang bersalin didapatkan 3800 (70\%) ibu khawatir dengan proses persalinan (Rendra, 2014).

Menurut Robbins dan Judge (2010) mengemukakan bahwa sikap ibu melakukan ANC dipengaruhi oleh karakteristik pribadi (kepribadian, motif, minat, kebutuhan, pengalaman masa lalu dan harapan seseorang) dan situasi (waktu, keadaan kerja dan keadaan sosial), sedangkan faktor lain yaitu tenaga bidan kurang respon terhadap keluhan pasien terutama pada saat pasien tidak bisa lagi ke sarana pelayanan, keterbatasan fasilitas yang dimiliki polindes. Kondisi tersebut yang mempengaruhi persepsi ibu negatif sehingga ibu tidak yakin untuk melakukan ANC. Selain itu, anggapan ibu tentang kondisi kehamilan yang baikbaik saja sehingga ibu tidak perlu melakukan pemeriksaan kehamilan ke petugas kesehatan yang dapat berdampak pada meningkatnya angka kematian ibu hamil karena kurangnya deteksi dini resiko tinggi (Winaryati, 2009). Beberapa faktor yang mempengaruhi keaktifan ibu dalam melakukan kunjungan ANC yaitu umur, pendidikan, paritas dan pekerjaan (Lumongga, 2013).

Dampak dari ibu hamil yang tidak mengikuti ANC adalah meningkatnya angka mortalitas dan morbilitas ibu, tidak terdeteksinya kelainan-kelainan kehamilan dan kelainan fisik yang terjadi pada saat persalinan tidak dapat di deteksi secara dini (Depkes RI, 2008). Selain itu ibu hamil kurang mendapatkan informasi tentang persiapan persalinan sehingga pada saat akan menghadapi persalinan kecemasannya meningkat.

Salah satu upaya telah dilakukan tenaga kesehatan untuk menurunkan angka kecemasan pada ibu hamil yaitu pendidikan kesehatan pada saat ANC. Ibu hamil dapat terhindar dari resiko-resiko buruk akibat kehamilan dengan cara melakukan pengawasan dengan baik terhadap kehamilan yaitu ibu melakukan kunjungan antenatal secara teratur dan rutin (Komariyah, 2014).. Kepatuhan dalam melakukan ANC akan meningkatkan pemahaman ibu tentang kehamilan, nifas dan persalinan sehingga ibu hamil akan mampu mengurangi kecemasan yang dialami dalam menjalani proses persalinan.

Dari uraian di atas maka penelitian tertarik untuk meneliti tentang Hubungan kepatuhan antenatale care (ANC) dengan kecemasan ibu hamil trimester III dalam menghadapi persalinan di Bidan Praktek Mandiri (BPM) Yuni Widaryanti Desa Sumber Mulyo Kecamatan Jogoroto Kabupaten Jombang.

\section{METODE PENELITIAN}

Desain penelitian ini adalah analitik korelasional dengan pendekatan Cross sactional desain. Variabel penelitian adalah variable independen kepatuhan ANC dan variable dependen kecemasan ibu hamil trimester III dalam menghadapi persalinan. Populasi dalam penelitian ini adalah semua 
ibu hamil primigravida trimester III Bulan Mei - Juni di Wilayah Kerja BPM Yuni Widaryanti Desa Sumber Mulyo Kec. Jogoroto Kab. Jombang sebanyak 30 orang. Teknik sampling yang digunakan adalah Total sampling. Alatukur yang digunakan adalah observasi dan kuesioner.

\section{HASIL PENELITIAN}

Hasil penelitian didapatkan data Umum responden di Bidan Praktek Mandiri Yuni Widaryanti Desa Sumber Mulyo Kecamatan Jogoroto Kabupaten Jombang tanggal 29 Mei - 10 Juni 2017sebanyak 30 orang.

Berdasarkan tabel 1 menunjukkan bahwa responden di BPM Yuni Widaryanti Desa Sumber Mulyo Kec. Jogoroto Kab. Jombang hamper seluruhnya responden berusia 20-35 tahun sebanyak 25 0rang $(83,3 \%)$,setengah responden berpendidikan SMP sebanyak 15 ( 50,0\%), dan hampi rsetengah responden tidakbekerja atau IRT sebanyak 13 orang $(43,3 \%)$.

Tabel 1 Distribusi frekuensi Data Umum responden di Bidan Praktek Mandiri Yuni Widaryanti Desa Sumber Mulyo Kecamatan Jogoroto Kabupaten Jombang tanggal 29 Juni - 10 Mei 2017

\begin{tabular}{clcc}
\hline No. & Data Umum & Frekuensi & Presentase (\%) \\
\hline 1 & Umur & 5 & \\
& $<20$ tahun & 25 & 16,7 \\
\multirow{2}{*}{2} & 20-35tahun & & 83,3 \\
& Pendidikan & 4 & 13,3 \\
& SD & 15 & 50,0 \\
& SMP & 11 & 36,7 \\
\multirow{2}{*}{3} & SMA & & 33,3 \\
& Pekerjaan & 10 & 23,3 \\
& Petani & 7 & 43,3 \\
& Swasta & 13 &
\end{tabular}

Sumber data primer 2017

Tabel 2 Distribusi frekuensi Kepatuhan Antenatal Care (ANC) di Bidan Praktek Mandiri Yuni Widaryanti Desa Sumber Mulyo Kecamatan Jogoroto Kabupaten Jombang tanggal 29 Juni - 10 Mei 2017

\begin{tabular}{cccc}
\hline No & Kepatuhan & Jumlah & Presentase (\%) \\
\hline 1 & TidakPatuh & 16 & 46,7 \\
2 & Patuh & 14 & 53,3 \\
& Total & 30 & 100,0 \\
\hline
\end{tabular}

Sumber data primer 2017

Tabel 3 Distribusi frekuensi Kecemasan Ibu Hamil Trimester III dalam Menghadapi Persalinan di Bidan Praktek Mandiri Yuni Widaryanti Desa Sumber Mulyo Kecamatan Jogoroto Kabupaten Jombang tanggal 29 Juni - 10 Mei 2017

\begin{tabular}{cccc}
\hline No & $\begin{array}{c}\text { Kecemasan dalam menghadapi } \\
\text { persalinan }\end{array}$ & Jumlah & Presentase (\%) \\
\hline 1 & Tidakcemas & 1 & 3,3 \\
2 & Cemassedang & 11 & 36,7 \\
3 & Cemasringan & 15 & 50,0 \\
4 & Cemasberat & 3 & 10,0 \\
& Total & 30 & 100,0 \\
\hline
\end{tabular}


Tabel 4 Tabulasi silang antara umur dengan kepatuhan di Bidan Praktek Mandiri Yuni Widaryanti Desa Sumber Mulyo Kecamatan Jogoroto Kabupaten Jombang tanggal 29 Juni - 10 Mei 2017

\begin{tabular}{|c|c|c|c|c|c|c|}
\hline \multirow{3}{*}{ Umur } & \multicolumn{4}{|c|}{ Kepatuhan } & \multirow{3}{*}{$\begin{array}{c}\text { Jumlah } \\
\mathrm{f}\end{array}$} & \multirow{3}{*}{$\frac{\text { Presentasi }(\%)}{\%}$} \\
\hline & \multicolumn{2}{|c|}{ Patuh } & \multicolumn{2}{|c|}{ Tidakpatuh } & & \\
\hline & $\mathrm{f}$ & $\%$ & $f$ & $\%$ & & \\
\hline$<20$ & 1 & 3,3 & 4 & 13,3 & 5 & 16,7 \\
\hline $20-35$ & 13 & 52,0 & 12 & 40,0 & 25 & 83,3 \\
\hline Total & 14 & 46,7 & 16 & 53,3 & 30 & 100,0 \\
\hline
\end{tabular}

Tabel 5 Tabulasi silang antara pendidikan dengan kepatuhan di Bidan Praktek Mandiri Yuni Widaryanti Desa Sumber Mulyo Kecamatan Jogoroto Kabupaten Jombang tanggal 29 Juni -10 Mei 2017

\begin{tabular}{ccccccc}
\hline \multirow{2}{*}{ Pendidikan } & \multicolumn{2}{c}{ Repatuhan } & \multicolumn{2}{c}{ Tidakpatuh } & Jumlah & Presentasi (\%) \\
& f & $\%$ & f & $\%$ & f & $\%$ \\
\hline SD & 0 & 0,0 & 4 & 13,3 & 4 & 13,3 \\
SMP & 5 & 16,7 & 10 & 33,3 & 15 & 50,5 \\
SMA & 9 & 30,0 & 2 & 6,7 & 11 & 36,7 \\
Total & 14 & 46,7 & 16 & 53,3 & 30 & 100,0 \\
\hline
\end{tabular}

Sumber data primer 2017

Tabel 6 Tabulasi silang antara pekerjaan dengan kepatuhan di Bidan Praktek Mandiri Yuni Widaryanti Desa Sumber Mulyo Kecamatan Jogoroto Kabupaten Jombangtanggal 29 Juni - 10 Mei 2017

\begin{tabular}{ccccccc}
\hline \multirow{2}{*}{ Pekerjaan } & \multicolumn{2}{c}{ Patuh } & \multicolumn{2}{c}{ Kepatuhan } & Jumlah & Presentasi (\%) \\
& f & $\%$ & f & $\%$ & f & $\%$ \\
\hline Petani & 1 & 3,3 & 9 & 30,0 & 10 & 33,3 \\
Swasta & 6 & 20,0 & 1 & 3,3 & 7 & 23,3 \\
IRT & 7 & 23,3 & 6 & 20,0 & 13 & 43,3 \\
Total & 14 & 46,7 & 16 & 53,3 & 30 & 100,0 \\
\hline
\end{tabular}

Sumber data primer 2017

Tabel 7 Tabulasi silang antara umur dengan kecemasan di Bidan Praktek Mandiri Yuni Widaryanti Desa Sumber Mulyo Kecamatan Jogoroto Kabupaten Jombang tanggal 29 Juni - 10 Mei 2017

\begin{tabular}{|c|c|c|c|c|c|c|c|c|c|c|}
\hline \multirow{3}{*}{ Umur } & \multicolumn{8}{|c|}{ Kecemasan } & \multirow{3}{*}{$\begin{array}{c}\text { Jumlah } \\
\text { f } \\
\end{array}$} & \multirow{3}{*}{$\begin{array}{c}\text { Presentase } \\
\%\end{array}$} \\
\hline & \multicolumn{2}{|c|}{$\begin{array}{l}\text { Tidak } \\
\text { cemas }\end{array}$} & \multicolumn{2}{|c|}{ Ringan } & \multicolumn{2}{|c|}{ Sedang } & \multicolumn{2}{|c|}{ Berat } & & \\
\hline & $\mathrm{f}$ & $\%$ & $\mathrm{f}$ & $\%$ & $\mathrm{f}$ & $\%$ & $\mathrm{f}$ & $\%$ & & \\
\hline$<20$ & 0 & 0,0 & 0 & 0,0 & 2 & 6,7 & 3 & 10,0 & 5 & 16,7 \\
\hline $20-35$ & 1 & 3,3 & 11 & 36,7 & 13 & 43,3 & 0 & 0,0 & 23 & 83,3 \\
\hline Total & 1 & 3,3 & 11 & 36,7 & 15 & 50,0 & 3 & 10,0 & 30 & 100,0 \\
\hline
\end{tabular}

Sumber data primer 2017

Tabel 8 Tabulasi silang antara pendidikan dengan kecemasan di Bidan Praktek Mandiri Yuni Widaryanti Desa Sumber Mulyo Kecamatan Jogoroto Kabupaten Jombang tanggal 29 Juni - 10 Mei 2017 


\begin{tabular}{|c|c|c|c|c|c|c|c|c|c|c|}
\hline \multirow{3}{*}{ Pendidikan } & \multicolumn{8}{|c|}{ Kecemasan } & \multirow{3}{*}{$\begin{array}{c}\text { Jumlah } \\
\mathrm{f}\end{array}$} & \multirow{3}{*}{$\begin{array}{c}\text { Presentase } \\
\%\end{array}$} \\
\hline & \multicolumn{2}{|c|}{$\begin{array}{l}\text { Tidak } \\
\text { cemas }\end{array}$} & \multicolumn{2}{|c|}{ Ringan } & \multicolumn{2}{|c|}{ Sedang } & \multicolumn{2}{|c|}{ Berat } & & \\
\hline & $\mathrm{f}$ & $\%$ & $\mathrm{f}$ & $\%$ & $\mathrm{f}$ & $\%$ & $\mathrm{f}$ & $\%$ & & \\
\hline SD & 0 & 0,0 & 1 & 3,3 & 3 & 6,7 & 0 & 0,0 & 4 & 13,3 \\
\hline SMP & 0 & 0,0 & 3 & 10,0 & 9 & 30,0 & 3 & 10,0 & 14 & 50,0 \\
\hline SMA & 1 & 3,3 & 7 & 23,3 & 3 & 10,0 & 0 & 0,0 & 11 & 36,7 \\
\hline Total & 1 & 3,3 & 11 & 36,7 & 15 & 50,0 & 3 & 10,0 & 30 & 100,0 \\
\hline
\end{tabular}

Tabel 9 Tabulasi silang antara pekerjaan dengan kecemasan di Bidan Praktek Mandiri Yuni Widaryanti Desa Sumber Mulyo Kecamatan Jogoroto Kabupaten Jombang tanggal 29 Juni - 10 Mei 2017

\begin{tabular}{ccccccccccc}
\hline \multirow{2}{*}{ Pekerjaan } & \multicolumn{9}{c}{ Tidak } & \multicolumn{2}{c}{ Ringan } & \multicolumn{2}{c}{ Sedang } & \multicolumn{2}{c}{ Berat } & Jumlah & Presentase \\
& \multicolumn{2}{c}{ cemas } & \multicolumn{1}{c}{ f } & & & & & & & \\
& $\mathrm{f}$ & $\%$ & $\mathrm{f}$ & $\%$ & $\mathrm{f}$ & $\%$ & $\mathrm{f}$ & $\%$ & $\mathrm{f}$ & $\%$ \\
\hline Petani & 0 & 0,0 & 2 & 6,7 & 7 & 23,3 & 1 & 3,3 & 10 & 33,3 \\
Swasta & 0 & 3,3 & 6 & 20,0 & 1 & 3,3 & 0 & 0,0 & 7 & 23,3 \\
IRT & 1 & 0,0 & 3 & 10,0 & 7 & 23,3 & 2 & 6,7 & 13 & 43,3 \\
Total & 1 & 3,3 & 11 & 36,7 & 15 & 50,0 & 3 & 10,0 & 30 & 100,0 \\
\hline
\end{tabular}

Sumber data primer 2017

Tabel 10 Tabulasi silang Kepatuhan Antenatal Care (ANC) Kecemasan Ibu Hamil Trimester III dalam Menghadapi Persalinan di Bidan Praktek Mandiri Yuni Widaryanti Desa Sumber Mulyo Kecamatan Jogoroto Kabupaten Jombang tanggal 29 Juni - 10 Mei 2017

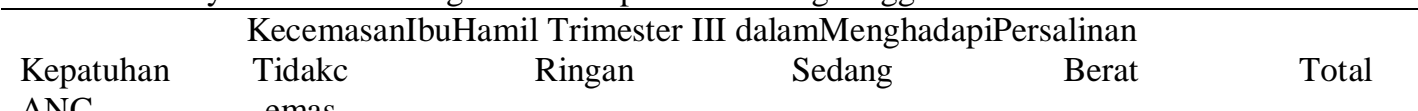

\begin{tabular}{|c|c|c|c|c|}
\hline \multirow[t]{2}{*}{ ANC } & \multicolumn{2}{|l|}{ emas } & \\
\hline & f & $\%$ & $\mathrm{f}$ & $\%$ \\
\hline Patuh & 1 & 7,1 & 8 & 57,1 \\
\hline TidakPatuh & 0 & 0 & 3 & 18,8 \\
\hline Total & 1 & 3,3 & 11 & 36,7 \\
\hline
\end{tabular}

Sumber data primer 2017

Berdasarkan tabel 2 dapat diketahui bahwa hamper setengahnya kepatuhan ibu hamil trimester III dalam melakukan antenatale care (ANC) adalah tidak patuh sebanyak 16 orang $(46,7 \%)$ dan patuh sebanyak 14 orang $(53,3 \%)$. Berdasarkan Tabel 3 dapat menunjukkan bahwa setengah responden memiliki kecemasan sedang dalam menghadapi persalinan sebanyak 15 responden $(50,0 \%)$ Berdasarkan Tabel 4 dapat menunjukkan bahwa hampir seluruhnya $(83,3 \%)$ responden berusia 20 35 tahun tidak patuh sebanyak 12 orang dan responden yang patuh sebanyak 13 orang. Berdasarkan table 5 menunjukkan bahwa hampir setengahnya $(50,0 \%)$ responden yang berpendidikan SMP tidak patuh sebanyak 10 orang. Berdasarkan table 6 menunjukkan bahwa hampir setengahnya

\begin{tabular}{cccccc}
$\mathrm{f}$ & $\%$ & $\mathrm{f}$ & $\%$ & $\mathrm{f}$ & $\%$ \\
\hline 4 & 28,6 & 1 & 7,1 & 14 & 46,7 \\
11 & 68,8 & 2 & 12,5 & 16 & 53,3 \\
15 & 50,0 & 3 & 10,0 & 30 & 100 \\
\hline
\end{tabular}

$(33,3 \%)$ responden yang bekerja petani tidak patuh sebanyak 9 orang. Berdasarkan table 7 menunjukkan bahwa bahwa setengahnya $(50,0 \%)$ responden mengalami kecemasan sedang sebanyak 15 orang, ringan 11 orang, dan berat 3 orang. Berdasarkan tabel 8 menunjukkan bahwa setengahnya $(50,0 \%)$ responden yang berpendidikan SMP memiliki kecemasan sedang sebanyak 9 orang. Berdasarkan tabel 9 menunjukkan bahwa hamper setengahnya $(33,3 \%)$ responden yang bekerja sebagai petani memiliki kecemasan sedang sebanyak 7 orang. Berdasarkan tabel 10 menunjukkan bahwa dari 14 kepatuhan ANC yang patuh, 8 orang $(57,1 \%)$ ibu mempunyai kecemasan ringan. Sedangkan dari 16 kepatuhan ANC yang tidak patuh sebagian besar ibu mengalami kecemasan sedang sebanyak 11 orang $(68,8 \%)$. 


\section{PEMBAHASAN}

\section{Kepatuhan ANC}

Berdasarkan hasil penelitian peneliti pada tabel 2 dapat diketahui bahwa hampir stengahnya ibu tidak patuh melakukan ANC sebanyak 16 orang $(46,7 \%)$. Menurut Niven (2013) kepatuhan adalah sejauhmana perilaku pasien sesuai dengan ketentuan yang diberikan oleh professional kesehatan. Begitu juga menurut Slamet, B. (2007) sebelumnya mengatakan kepatuhan (ketaatan) adalah sebagai tingkat penderita melaksanakan cara pengobatan dan prilaku yang disarankan oleh dokter atau orang lain.

Hasil penelitian ini menunjukkan kesesuaian dengan teori (Depkes RI,2012) faktor yang mempengaruhi kepatuhan antenatal care meliputi faktor internal meliputi usia, paritas dan pendidikan. Sedangkan faktor eksternal meliputi: pengetahuan, sikap, ekonomi, sosial budaya, geografis, informasi, dan dukungan.

Berdasarkan data diatas ketidakpatuhan yang cukup besar itu sangat mungkin dipengaruhi oleh usia, pendidikan dan pekerjaan dari responden tersebut. Kepatuhan ANC dipengaruhi oleh umur, semakin cukup umur, tingkat kematangan seseorang akan lebih di percaya daripada orang yang belum cukup tinggi kedewasaanya. Hasil penelitian ini menunjukkan kesesuaian dengan teori Purwanto (2010) yang menyatakan bahwa semakin cukup umur, tingkat kematangan dan kekuatan seseorang akan lebih matang dalam berpikir dan bekerja. Kepatuhan ANC juga dipengaruhi oleh tingkat pendidikan seperti pada tabel 5. Hasil penelitian ini menunjukkan kesesuaian dengan teori Sunaryo (2012) yang menyatakan bahwa rendahnya pendidikan akan mempengaruhi kemampuan ibu dalam mencerna dan menyerap informasi baru sehingga akan mempengaruhi terbentuknya sikap seseorang. Faktor lain yang mempengaruhi kepatuhan ANC adalah pekerjaan seperti pada tabel tabel 6 hampir setengahnya responden bekerja sebagai petani, dimana diketahui responden yang bekerja sebagai petani banyak aktivitas di lahan jadi tidak ada waktu untuk memeriksakan kehamilan ke sarana kesehatan dan juga setelah kerja responden lebih mengutamakan beristirahat dari pada melakukan aktivitas lain. Hal ini menunjukkan bahwa status pekerjaan ibu berpengaruh pada keteraturan ibu untuk melakukan ANC.

\section{Kecemasan ibu hamil dalam menghadapi persalinan.}

Berdasarkan hasil penelitian peneliti pada tabel 3 dapat diketahui bahwa bahwa setengahnya $(50,0 \%)$ responden mengalami kecemasan sedang sebanyak 15 orang.

Kecemasan merupakan suatu perasaan waswasseakan sesuatu yang buruk akan terjadidan merasa tidak nyaman seakan adaancaman. Seorang ibu mungkin merasakantakut akan rasa sakit dan bahaya fisik yangakan timbul pada waktu persalinan (Wiyono, \& Susanti, 2011). Kecemasan yang terjadi pada wanita yang akan melahirkan, umumnya disebabkan karena mereka harus menyesuaikan diri dengan perubahan fisik dan psikologis bayiyang banyak menyita waktu, emosi dan energi (Lalita, 2013).

Berdasarkan hasil penelitian peneliti pada tabel 7 menunjukkan bahwa hampir seluruhnya $(83,3)$ responden berusia 20- 35 tahun memiliki kecemasan sedang sebanyak 13 orang, dan responden berusia $<20$ tahun memiliki kecemasan sedang sebanyak 2 orang. Ibu yang baru akan memiliki anak tidak mempunyai pengalaman tentang kehamilan, persalinan dan nifas sehingga ibu akan mengalami kecemasan dalam menghadapi persalinan. Umur dan pendididkan ibu juga sangat mempengaruhi kecemasan ibu, seperti pada usia ibu yang produktif yaitu usia 20-35 tahun menyebabkan ibu mengerti tentang kondisi kesehatan dan pentingnya untuk melakukan ANC. Ibu mampu berpikir secara rasional tentang pentingnya ANC dan sangat mudah sekali menyerap dan menyaring informasi seputar kehamilannya sehingga mengurangi kecemasan. Hasil ini sesuai dengan teori dari Depkes RI (2012) yang menyatakan bahwa semakin cukup umur, tingkat kematangan seseorang akan lebih di percaya daripada orang yang belum cukup tinggi 
kedewasaanya, jika kematangan usia seseorang cukup tinggi maka pola berfikir seseorang akan lebih dewasa.

Berdasarkan tabel 8 menunjukkan bahwa sebagian besar responden yang berpendidikan SMP memiliki kecemasan sedang sebanyak 9 orang $(60,0 \%)$. Ibu yang berpendidikan rendah tidak tahu apakah ibu masuk kedalam golongan resiko tinggi atau tidak. Hal ini sesuai dengan teori dari Depkes RI (2012) yang menyatakan bahwa ketidakmengertian ibu dan keluarga terhadap pentingnya pemeriksaan kehamilan berdampak pada ibu hamil tidak memeriksakan kehamilannya pada petugas kesehatan.

Perasaan cemas yang seringkali menyertaikehamilan akan mencapai puncaknya padasaat persalinan. Persalinan merupakan suatupengalaman yang membutuhkan kerja kerasdan perjuangan yang melelahkan bagi ibu(Dairi, 2011).Bayangan risiko akan kematian ketikamelahirkan semakin mempengaruhikestabilan emosi ibu. Jika kondisi emosi yangtidak stabil ini dibawa terus sampai padaproses persalinan, dapat menyebabkanpersalinan tidak lancar. Selain itu, banyak ibuyang merasakan sakit saat bersalin lebihparah dari seharusnya karena banyakdipengaruhi oleh rasa panik dan stress(Abidin, 2010).

Menrut peneliti,hal ini dikarenakan ibu yang baru akan mempunyai anak tidak memiliki pengalaman tentang proses persalinan sehingga membuat ibu semakin cemas dalam menghadapi persalinan.

Hubungan kepatuhan antenatal care (ANC) dengan kecemasan ibu hamil trimester III dalam menghadapi persalinan di Desa Sumber Mulyo Kec. Jogoroto Kab. Jombang.

Berdasarkan hasil penelitian diketahui bahwa dari 16 responden yang tidak patuh melakukan ANC mempunyai kecemasan sedang sebanyak 11 orang $(68,8 \%)$. Sedangkan dari 14 responden yang patuh melakukan ANC mempunyai kecemasan ringan sebanyak 8 orang $(57,1 \%)$.
Berdasarkan hasil uji statistik Spearman rank diperoleh hasil 0,433 dengan angka signifikan atau nilai probabilitas sebesar 0,017 jauh lebih kecil dari nilai alpha $(\alpha) 0,05$ atau $(\rho<\alpha)$. Karena $(0,017<0,05)$, maka hipotesis $\mathrm{H} 1$ diterima, artinya ada hubungan kepatuhan antenatal care (ANC) dengan kecemasan ibu hamil trimester III dalam menghadapi persalinan di Bidan Praktek Mandiri (BPM) Desa Sumbermulyo Kecamatan Jogoroto Kabupaten Jombang. Hasil uji tersebut juga diketahui tingkat hubungan sebesar 0,433 berarti antara angka 0,400-0,599 maka dikatakan kategori Sedang.

Menurut Robbins dan Judge (2010) mengemukakan bahwa sikap ibu melakukan antenatal care dipengaruhi oleh karakteristik pribadi (kepribadian, motif, minat, kebutuhan, pengalaman masa lalu dan harapan seseorang) dan situasi (waktu, keadaan kerja dan keadaan sosial). Selain itu, anggapan ibu tentang kondisi kehamilan yang baik-baik saja sehingga ibu tidak perlu melakukan pemeriksaan kehamilan ke petugas kesehatan yang dapat berdampak pada meningkatnya angka kematian ibu hamil karena kurangnya deteksi dini resiko tinggi (Winaryati, 2009). Beberapa faktor yang mempengaruhi keaktifan ibu dalam melakukan kunjungan antenatal care yaitu umur, pendidikan, paritas dan pekerjaan (Lumongga, 2013). Tingkat kecemasan pada ibu hamil juga dapat dipengaruhi oleh kurangnya informasi yang diperoleh selama kehamilan. Kurangnya pengetahuan akan perilaku-perilaku yang berkaitan dengan kesehatan reproduksi serta minimnya informasi yang diperoleh selama masa kehamilan akan menimbulkan kecemasan tersendiri (Aisyah, 2009).

Menurut peneliti, kecemasan ibu dalam menghadapi persalinan dikarenakan jadwal persalinan yang semakin dekat terutama pada persalinan pertama, wajar timbul perasaan cemas ataupun takut meskipun ingin segera melepaskan beban dari perutnya yang membesar, dilain pihak timbul kekhawatiran pada kelancaran pada persalinan. Ibu hamil dapat mengalami kecemasan saat akan menghadapi persalinan 
merupakan hal yang wajar karena segala sesuatunya merupakan pengalaman baru bagi ibu. Tetapi sebagian ibu beranggapan bahwa kondisi kehamilannya yang baik-baik saja sehingga ibu tidak perlu melakukan pemeriksaan kehamilan ke petugas kesehatan.

\section{KESIMPULAN DAN SARAN}

Hubungan kepatuhan antenatal care (ANC) dengan kecemasan ibu hamil trimester III dalam menghadapi persalinan di Desa Sumber Mulyo Kec. Jogoroto Kab. JombangBulan Mei - Juni 2017 diperoleh kesimpulan sebagai berikut :

1. Kepatuhan antenatale care (ANC) di Bidan Praktek Mandiri (BPM) Yuni Widaryanti Desa Sumbermulyo Kec. Jogoroto Kab.Jombang setengah (53,3\%) respondenadalah tidak patuh sebanyak 16 orang.

2. Kecemasan ibu hamil trimester III dalam menghadapi persalinan di Bidan Praktek Mandiri (BPM) Yuni Widaryanti Desa Sumbermulyo Kec. Jogoroto Kab.Jombang setengah $(50,0 \%)$ respondenadalah cemas sedang sebanyak 15 orang.

3. Adanya hubungandengantingkatkolerasisedang antara kepatuhan antenatal care (ANC) dengan kecemasan ibu hamil trimester III dalam menghadapi persalinan di Bidan Praktek Mandiri (BPM) Yuni Widaryanti Desa Sumbermulyo Kec. Jogoroto Kab.Jombang dengannilaisignifikan 0,017 dankolerasi 0,433 yang dibuktikan dari uji Rank Spearman $\rho<\alpha$ yaitu $0,017<0,05$ maka $\mathrm{H}_{1}$ diterima.

\section{Saran}

1. Bagi institusi Kesehatan / Teoritis

Peneliti mengharapkan agar institusi untuk lebih banyak menambah dan memperkaya konsep-konsep teori yang dapat menyongsong perkembangan ilmu kesehatan khususnya ilmu kebidanan guna untuk menambah pengetahuan ibu hamil.

2. Bagi Tenaga Kesehatan/ praktis
Diharapkan tenaga kesehatan dapat meningkatkanketerampilan yang dimiliki, memberikan informasi selengkapmungkinuntukmemotivasikunj ugankehamilansehinggameningkatkanpe mahaman yang baiktentang antenatale care (ANC) pada ibu hamil dan memberikan asuhan keperawatan sesuai standar dengan memperhatikan kebutuhan ibu hamil.

3. Bagi Responden

Lebih termotivasi lagi dalam melakukan pemeriksaan kehamilan agar ibu dapat menjaga kondisi kesehatan dan janin yang di kandung serta mampu mengatasi kecemasan ibu pada saat menghadapi persalinan sehingga dapat membantu proses kelancaran persalinan.

4. Bagi Tempat Penelitian (BPM)

Diharapkan BPM mampu meningkatkan pelayanan pada saat antenatal care terpadu pada BPM itu sendiri dalam rangka mendeteksi penyakit penyerta lainnya pada ibu untuk menurunkan angka kematian ibu dan bayi serta kecemasan ibu dalam menghadapi persalinan.

5. BagiPeneliti

Diharapkan mahasiswa lebih dapat berkomunikasi dengan baikpada ibu dan masyarakat dalam memberikan health education mengenai antenatale care (ANC) dengan empati dan tanggung jawab yang baik.

6. Bagi Peneliti Selanjutnya

Diharapkan dari penelitian ini dapat member masukan dan sebagai referensi untuk melaksanakan penelitian lebih lanjut mengenai faktor lain yang mempengaruhi hubungan kepatuhan antenatale care (ANC) dengan kecemasan ibu hamil trimester III dalam menghadapi persalinan.

\section{DAFTAR PUSTAKA}

Agustina, L. 2012.Pengaruh SenamLansiaAzwar, Saifudin. 2012. Skala Pengukuran Psikologis. Jakarta: ALFABETA

Abidin, 2010. Jurnal Penelitian Hubungan Dukungan Suami dengan Kecemasan Ibu Menjelang 
Persalinan. www.unsu.ac.id diakses tanggal 10 April 2016

Aryastiani.2014. Perubahan Posikologis pada Masa kehamilan Dan Persalinan. Jakarta: EGC

Arikunto, S. 2012. Prosedur Penelitian

Suatu Pendekatan Praktik. Jakarta : PT.

Rineka Medika

Depdiknas. 2012. Prevalensi Angka Kematian Ibu. www.depkes.ri.ac.iddiakses tanggal 20 Maret 2015

Desmita. 2013. Psikologi Perkembangan. Jakarta: PT. Rineka Cipta

Dinkes Jatim. 2015. Standar Pelayanan Minimal Bidang Kesehatan Propini Jatim. www.dinkesjatim.go.id diakses tanggal 10 Januari 2016

Hidayat, A. Azis Alimul. 2012. Buku Metode Penelitian Kesehatan Paradigma Kuantitatif. Jakarta: Salemba Medika, pp. 38

Hidayat, A. Aziz Alimul. 2008. Riset Keperawawatan dan Teknik Penulisan Ilmiah. Jakarta : Salemba Medika

Hartoyo. 2013. Kecemasan. Jakarta: PT. RINEKA CIPTA

Intan. 2014. Kepatuhan Ibu dalam Melakukan ANC. www.uns.ac.iddiakses tanggal 10 Januari 2016

Januaridi. 2014. Faktor-Faktor yang Mempengaruhi ANC. Jurnal Kebidanan Unsu (the Unsu Joernal of Midwifery), Volume 3, No 2. Sumatera: Universitas Sumatera Utara (UNSU)

Kemenkes RI. 2015. Survei Cakupan Kunjungan Kl dan K4. www.kemenkes-ri.co.iddiakses tanggal 10 Januari 2016

Marmi. 2013. Keperawatan Maternitas. Yogyakarta: Graha Ilmu
Nazir. 2010. Metode penelitian .Bogor : Ghalia Pustaka Utama

Niven. 2013. Psikologi Pendidikan dan Kesehatan. Jakarta: EGC

Notoatmodjo, S. 2010. Metodelogi Penelitian Kesehatan. Jakarta: PT. RinekaCipta, pp. 32

.2012. Kesehatan Masyarakat Ilmu dan Seni. Jakarta: PT. RinekaCipta

Nursalam. 2013. Konsep dan Penerapan Metodologi Penelitian Iimu Keperawatan. Jakarta: Salemba Medika

Nasution. 2013. Kriteria Kecemasan dan pengukuranya. www.uns.ac.id. Akses 3 Januari 2016

Nasution. 2013. Kriteria Kecemasan dan pengukuranya. www.uns.ac.id. Akses 3 Januari 2016

Prawirohardjo, Sarwono. 2009. Ilmu Kandungan. Yayasan Bina Pustaka Sarwono Prawirohardjo. Yogyakarta

Purwanto. 2012. Psikologi Umum. Jakarta: PT. Rineka Cipta

Rendra. 2014. Kecemasan Pada Masa Persalinan. www.unsu.ac.id. akses 3 Januari 2016

Salmah. 2013. Psikologi Ibu dan Anak. Yogyakarta: Graha Ilmu

Sarwono, Sarlito. 2009. Ilmu Kebidanan. Yogyakarta: YBPSP

Solihah. 2009. Asuhan Ibu Hamil. Yogyakarta: Graha Ilmu

Sugiyono. 2010. Statistik Penelitian untuk Kesehatan. Bandung: Alfabeta

Sunaryo. 2012. Psikologi Kesehatan Keperawatan. Jakarta: EGC

Susanti. 2013. Hubungan Pengetahuan dengan Sikap Ibu Melakukan ANC. Jurnal Kebidanan Unsu (the Unsu Joernal of Midwifery), Volume 2, No 3. Sumatera: 
Universitas Sumatera Utara

(UNSU)

Syaifudin. 2012. Sikap dan Perilaku. Jakarta: PT. Rineka Cipta

Winaryati. 2009.Buku Ajar Konsep Kebidanan. Jakarta: EGC

Wiyono, \& Susanti, 2011. Faktor-faktor yang mempengaruhi kecemasan pada ibu bersalin kala I fase Laten. www.unjem.ac.iddiakses tanggal 12 April 2016

Zulfiqar. 2012. Pemeriksaan Kehamilan. Yogyakarta: Fitramaya 